\title{
Profiling teachers based on their professional attitudes towards teaching responsible research and innovation
}

\author{
Miikka de Vocht and Antti Laherto \\ Department of Physics, University of Helsinki, Helsinki, Finland \\ For correspondence: miikka.devocht@helsinki.fi
}

\begin{abstract}
In order to facilitate policy-driven reforms in science education, it is important to understand how teaching innovations diffuse among teachers and how that adoption process can be catalysed. Little is known about the set of attitudes that makes teachers early or late adopters. In this study, the Concerns-Based Adoption Model (C-BAM) was employed as a framework for analysing teachers' interests, concerns, worries and enthusiasm. We argue that the questionnaire typically used with C-BAM suffers from a ceiling effect and has unbalanced variables. An improved version of the questionnaire was developed and implemented in the project IRRESISTIBLE with 180 science teachers in ten countries at all school levels. The case of educational innovation in this project was Responsible Research and Innovation (RRI), a concept offered by the EU for science education to orient towards socially and ethically sensitive and inclusive processes of science and technology. Using cluster analysis we found four concern profile types: the Carefree, the Pragmatic, the Uncertain and the Worried. With their relatively high positive interests, the Carefree and the Pragmatic profile types are most likely to be early adopters. The high number of Uncertain teachers calls for better conceptualization of RRI in the school context. Furthermore, teacher professional development and additional resources are needed if this innovation is to be diffused widely across European schools. The improved questionnaire provided elaborate information on teachers' concerns and interests, and could help in understanding and facilitating other top-down educational reforms as well.
\end{abstract}

Keywords: teacher attitudes, responsible research and innovation, concerns-based adoption model, diffusion of innovations

\section{Introduction}

\section{The problem}

Teachers are gatekeepers to any top-down teaching innovation or educational reform (Anderson \& Helms, 2001; van Driel, Beijaard, \& Verloop, 2001). In order to facilitate policy-driven changes in teaching contents and practices, it is beneficial to understand how such innovations diffuse among teachers and how this process can be catalysed. According to the Diffusion of Innovations model by Rogers (2003) - one of the best-known and most widespread models in social sciences - the rate of adopting an innovation among potential adopters follows a normal distribution as a function of time. The initial spreading in a successful adoption process is quick among early adopters or forerunners, and slows down once a majority has adopted the innovation. Many factors affect the diffusion process, such as the innovation itself, how the innovation is communicated and the social setting. Very importantly, negative attitudes towards an innovation increase levels of emotional exhaustion and disengagement from the innovation, and can even lead to burnout (Evers, Brouwers, \& Tomic, 2002). Therefore, negative attitudes hinder teachers' ability to adopt and operationalize the innovation. To understand educational reforms and make them more effective, teachers' professional attitudes must be investigated and their concerns addressed. To this end, the research reported here contributed to the development of an instrument for profiling teachers on the basis of their professional attitudes towards an educational innovation. 
Attitude is a complex psychological construct that cannot be observed directly. Attitudes exist in cognitive, affective, behavioural, professional, personal, conscious and unconscious levels, and many of these are difficult or even impossible to measure. In this study, we employed the Concern-Based Adoption Model (C-BAM) (Hall, George, \& Rutherford, 1977; Shoulders \& Myers, 2011), which assumes that teachers' interests and concerns reflect their attitudes. Some teachers are more enthusiastic than others, while others tend to have more concerns or worries towards new teaching approaches. More specifically, C-BAM divides concerns into six stages:

- Informational - Do I know enough about the innovation?

- Personal - Am I competent in the context of the innovation?

- Management - Do I have enough time and resources for the innovation?

- Consequence - How will the innovation affect my lessons and the working environment?

- Collaboration - Can I find colleagues and experts to work with?

- Refocusing - Can I improve the innovation further?

Earlier experiences with C-BAM (e.g. de Vocht, Laherto, \& Parchmann, 2015; de Vocht, Laherto, \& Parchmann, submitted) have indicated a need to improve the Stages of Concern (SoC) questionnaire typically used to operationalize the model. There are two major validity issues with the original questionnaire. The questionnaire does not separate negative and positive concerns, but rather has them mixed within a variable representing a concern stage. Therefore, if teachers have significant concerns, for example, in the personal stage, it is difficult to know if this is because they want to develop themselves or if they have self-efficacy issues. The second issue is that the type of items in the various stages differ greatly, making comparison of concern stages difficult. Therefore, in the study reported here, we first set out to improve the questionnaire.

Through the development of the SoC questionnaire, we aimed at creating a tool for getting more elaborate information on teacher concerns and interests. We aimed to identify clusters of teachers and their concern/interest profile type, which may relate to characterising teachers as forerunners or late adopters in the Diffusion of Innovations model. Such information, we argue, could prove beneficial in adapting/improving teachers' professional development in order to facilitate the adoption of teaching and learning innovations.

\section{The context of the study}

The case of teaching/learning reform in this research was Responsible Research and Innovation (RRI), a concept offered by the European Union (EU) for science education to orient towards socially and ethically sensitive and inclusive processes of science and technology (Sutcliffe, 2011, van den Hoven \& Jacob, 2013). RRI is a major cross-cutting issue of the Horizon 2020 programme and also a key concept in calls related to science education. Through a number of EU-funded initiatives, RRI is likely to have a substantial influence on teacher professional development and science classrooms across Europe. Even though RRI includes some elements that are not novel for all science teachers (e.g. understanding on how science interacts with society, and the need to increase student engagement in science), teaching the full set of ideas entailed by this concept requires a change in teachers' thinking. This change then enables the adoption of an innovation.

In general, there are two different approaches to RRI. The first one sees RRI as a normative set of keypoints: the consistent, ongoing engagement of all societal actors - such as academia, industry, policy makers, NGO's and civil society - in the research and innovation process; equality to unlock the full potential of individuals regardless of their gender or background; science education to better equip future researchers and other societal actors with the necessary knowledge and tools to fully participate and take responsibility in the research and innovation process; promoting open access, transparency and accessibility to boost innovation and increase the use of scientific results by all societal actors; ethical issues i.e. the deliberate focus of research and innovation on achieving 
increased social or environmental relevance, acceptability and benefit; and governance models for integrating all RRI elements with adaptable and better oversight mechanisms to anticipate and manage problems and opportunities (Sutcliffe, 2011). The second approach to RRI emphasises shared values between the aforementioned societal actors. Reforms may not always be directly beneficial for everyone, and societal actors have to compromise and collaborate in finding the best solutions (Ruggiu, 2015).

Since the views of future generations strongly affect how RRI ideas spread throughout society, in the H2020 programme, the EU wants to diffuse RRI in schools as teaching content. However, this is difficult if teachers themselves hold an unfavourable attitude towards it. Other pitfalls exist as well, such as improper resources for diffusing RRI, lack of teacher competency or conflicts with the curriculum. Our study, however, focuses on examining teacher attitudes towards these competencies. Although professional skills are important, teacher attitudes towards a teaching innovation might be equally important. Teacher perspectives on RRI have only recently started to be investigated (de Vocht, Laherto, \& Parchmann, 2015; de Vocht, Laherto, \& Parchmann, submitted).

This research was carried out as part of the EU-funded project IRRESISTIBLE (2013-2016), which aimed at incorporating RRI in science classrooms through teacher professional development organized in nine European countries and Israel. The data reported in this paper was obtained from participating teachers at an early phase of the process. Afterwards, the surveyed teachers familiarized themselves with the concept of RRI and designed teaching modules on RRI. The modules aimed to bring cutting-edge science into school contexts, promote inquiry-based learning and combine inschool and out-of-school learning as well as formal and informal learning.

\section{Research questions}

This research set out to improve the Stages of Concern questionnaire for the abovementioned purposes. With the improved questionnaire, we profiled teachers' concerns about RRI teaching. The purpose was not only to facilitate RRI teaching, but also to learn about teacher concern profiles at a general level, which may help with understanding and facilitating other top-down educational reforms as well. The research addressed the following questions:

- RQ1. How can the Stages of Concern questionnaire be improved as a tool to profile teachers according to their concerns about teaching and learning innovations?

- RQ2. What kind of concern profiles, regarding teaching RRI, does the elaborated Stages of Concern questionnaire reveal?

- RQ3. How can teacher concern profiles be taken into account when facilitating the adoption of teaching and learning innovations?

We address RQ1 in the following sections by arguing the shortcomings of the original SoC questionnaire. This critique is mostly based on the results of our previous study, as well as other literature. We will also explain the changes made to the questionnaire, which was used for the empirical part of this study. Thereafter, we present the empirical part of this study in order to answer RQ2. We conclude by elaborating these results, referring to our theoretical framework and earlier literature to address RQ3.

\section{Theoretical background}

According to the Diffusion of Innovations model, the best way to diffuse an innovation is to involve opinion leaders, innovators and early adopters (Rogers, 2003). However, it is difficult to identify reliably the attributes that define an early adopter. Rogers' adopter categorisation (early adopters, early majority, late majority, laggards) is based on the time of adopting an innovation, as opposed to e.g. personal traits or social capital. Early adopters are simply the ones who adopt before the majority 
(Frank, Zhao \& Borman, 2004). One of the weaknesses of the Diffusion model is that it addresses psychological reasons behind adopter categories in an unspecific and general manner. The issue of whether or not - and how - early adopters' psychological traits differ from the rest could be a valuable addition to Rogers' model. One of the aims of this study is to discuss the connections between teacher attitudes and concerns using Rogers' adopter categories.

Because of their complex nature, attitudes are difficult to define and even more difficult to measure. One of the few agreements that attitude research can reach, is that it is possible to divide attitudes into cognitive, affective and behavioural components (van Aalderen-Smeets, Walma van der Molen, J. H., \& Asma, 2011). For example, one can have negative attitudes towards snakes, because they know that some snakes are venomous (cognitive) and/or because one very much dislikes snakes (affective). These attitudes can, however, result in many types of behaviour, which may or may not reflect the cognitive and affective components of the attitudes (Eagly, 1992). An outside observer can incorrectly interpret a certain kind of behaviour as a result of an individual's attitudes, even if this behaviour stems from other sources, such as peer pressure. The Concerns-Based Adoption Model tries to circle around this problem by arguing that teacher concerns, interests, worries and enthusiasm can partly reflect their attitudes. Concern is, however, a broader concept than attitude, which should be kept in mind when drawing conclusions from the results of this study.

The Concerns-Based Adoption Model (C-BAM) argues that concerns, interests, worries and enthusiasm are important factors when adopting an innovation (Hall, 1977). C-BAM has been around for about as long as the Diffusion of Innovations model, but has never received similar attention or recognition. C-BAM argues that teacher concerns about a particular subject guides the diffusion process. Some teachers are concerned about informational, practical and management issues more than others. Some teachers are concerned about their personal readiness and competency in teaching a certain subject. Others focus mainly on consequential concerns related to changes in their working environment. Still other concerns exist, such as motivation to collaborate with colleagues or experts outside the school. Some teachers are also looking for ways to improve and refocus their teaching and the content they are familiar with. A typical C-BAM study would measure concerns in 7 stages; awareness, information, personal, management, consequence, collaboration and refocusing. The awareness stage is, however, often discarded for two reasons. Firstly, being aware or unaware is not really a concern in the same way as the other stages (although one can be concerned about being aware). Secondly, the information stage overlaps with the awareness stage, because as information increases awareness increases also.

Traditionally, C-BAM expects a shift from self- and task-concerns towards impact-concerns as time progresses. In the beginning, teachers are internalising the concept and have little energy left for collaboration, refocusing or being concerned about the consequences of a teaching innovation. If teachers' information, personal and management concerns are resolved sufficiently, they can then focus on the consequence, collaboration and refocusing concerns. Some studies have shown this direction for change (Overbaugh \& Ruiling, 2008; Tunks \& Weller, 2009), while others fail to detect it (Kwok, 2014; Newhouse, 2001). Instead of focusing on the development of concerns over time, this study aims to describe teachers' concern profiles before the adoption process. The pre-post comparison of our teachers has been left for future studies.

Another viewpoint suggests that teachers can have concerns in all concern stages simultaneously. Each teacher has his/her own individual concern profile, which might or might not change during the adoption process. Four concern profiles have been identified in previous research; the Resistor, the Co-operator, the Ideal Implementer and the Overachiever (Hollingshead, 2009). Resistors, for example, focus mainly on management concerns. They see that there are too many practical issues in the way of an innovation. Teachers who are Resistors are also likely to be laggards (Rogers, 2003), and 
generally adopt new innovations only after the Ideal Implementers. Ideal Implementers have few concerns in the information, personal and management stages and may be comparable to early adopters. The context dependency of the adopter categories in both frameworks is also an interesting question, since teachers may have different concern profiles depending on the teaching innovation in question. The content-specific results of this study in answering RQ2 only apply to the teaching of RRI, but the potential for generalizations is discussed too.

\section{Shortcomings of the Stages of Concern questionnaire}

In our previous study we implemented the traditional version of the Stages of Concern (SoC) questionnaire (Hall, 1977), which consists of 30 Likert scale items across the 6 stages; information, personal, management, consequence, collaboration and refocusing (de Vocht, Laherto \& Parchmann, submitted). The teachers filled in the questionnaire before they designed and implemented RRI content into teaching modules. These modules considered RRI issues in the context of cutting-edge science, such as nanotechnology and climate change. The results showed that the forerunner teachers are willing to find information and collaborate on RRI teaching; they believe that RRI can engage students and be a worthwhile part of the curriculum. Yet, the respondents voiced personal concerns about their ability to teach RRI, and only few concerns were resolved during the professional development period. All in all, the results were similar to many other studies in which most teachers have the so-called M-shape profile of the Co-operator (Hollingshead, 2009; Overbaugh \& Ruiling, 2008). This means that teachers are interested in learning more about RRI and collaborating on its teaching. Our previous results also demonstrate that the customary questionnaire used with C-BAM presents a consistent picture of teacher concerns, but does not differentiate teachers enough in order to formulate a statistically sound clustering of concern profiles. We argue that with proper adjustments, the questionnaire can provide more diverse and informational profiling of teacher concerns.

The first issue with the questionnaire is that it does not separate positive and negative concerns. The information stage, for example, inquires only about positive concerns or interests. Most items in this stage are formulated in a similar fashion as in the item 'I would like to know more about RRI topics myself'. The collaboration stage also only has items that inquire about positive concerns. The other stages focus more on negative concerns or worries. For example, an item in the management stage says 'I am concerned about not having enough time to teach RRI well', which is clearly a negative concern. Furthermore, most of the stages mix negative and positive items together, which makes the analysis difficult. Teachers with similar scores in a concern stage might have a different composition of negative and positive concerns. Therefore, in the new questionnaire, we differentiated negative and positive concerns into separate variables.

The second issue with the questionnaire is that it has an uneven formulation of items across the stages. Because the information stage has only positive items, whereas the personal stage has only negative or neutral items, these stages are not comparable. For example, if a teacher has a higher concern intensity in the personal stage than in the information stage, we cannot really know what this means. In the new questionnaire, we solved this issue by picking items that work well and creating similar items in the other concern stages. Another issue with the questionnaire was a ceiling effect. Some of the items, especially in the positive end of the spectrum, where too easy to agree with, which resulted in teachers using only the positive end of the Likert scale. We solved this issue by picking items that were not as easy to agree with. This should result in data that is statistically superior to the old questionnaire and more clearly differentiates between teachers. 


\section{The new questionnaire}

The improved Stages of Concern questionnaire, developed in this study, is presented in Appendix A. The most apparent change we made was the division of concerns into negative (worries) and positive (interest). Each negative stage has three items, one of which is a direct claim, such as 'I do not have...', 'I am not...', or 'I do not think...'. The remaining negative items start with 'I am concerned...', and inquire about concern more specifically. Each positive stage has two items, one of which is a general claim about the teacher's interest, while the other inquires about interest related to RRI teaching. The reason for having fewer positive than negative items (in addition to limiting the length of the questionnaire) was that the positive items are more likely to produce a ceiling effect, thus differentiating teachers less than the negative items. To improve comparability, we created similar items across the stages as much as possible. Therefore, each stage has five corresponding items (see Appendix A). For example, the Personal Stage item 16 - I am not competent in teaching RRI, corresponds to item 5 . I do not have enough knowledge of RRI.

Responses to the items were on a 7-point Likert scale ranging from $-3=$ strongly disagree to $3=$ strongly agree. Therefore positive values in the negative items indicate concern or worry and positive values in the positive items indicate interest or enthusiasm. Negative values in turn indicate a lack of these types of concerns or interests. One might incorrectly suspect that agreement with negative items is the same as disagreement with positive items, but this is not the case since a lack of worry does not automatically entail the presence of interest.

The new questionnaire affects the subsequent analysis in the following steps (the method of analysis is further explained in the following section):

1. Each group of items constructs a sum variable, which represents the respondent's concern intensity in a particular stage.

2. The positive and negative variables are grouped together to produce a negative concern profile and a positive concern profile separately for each respondent.

3. Clusters of teachers and their average scores are identified separately for the negative and positive profiles using cluster analysis.

4. The negative and positive cluster memberships are combined to find the distribution of different overall concern profiles.

\section{Method}

In late 2015 and early 2016, 180 teachers took 15 to 20 minutes to fill in the revised questionnaire. Most teachers filled in the questionnaire during one of their first Community of Learners (CoL) meetings in the IRRESISTIBLE project and had a general understanding of RRI by that time. The CoLs were at the beginning of the planning phase and were supposed to include RRI in the IRRESISTIBLE teaching modules later in the project. Most CoLs consisted of about 20 teachers and a few other experts from various fields (scientists, science education experts and museum experts). 97 teachers taught chemistry, 47 biology, 45 general science, 39 physics, and few teachers also taught mathematics, geography or another subject. 106 teachers taught at the upper secondary level, 67 at the lower secondary level and 25 at the primary school level. 39 teachers were from Turkey, 31 from Greece, 28 from the Netherlands, 26 from Poland, 19 from Italy, 17 from Finland, 9 from Portugal, 7 from Israel and 2 from Germany. 128 of the teachers were female, 51 were male, and one did not specify a gender. The online questionnaire was translated into each country's local language, with the exception of Italy and the Netherlands. Teachers from these countries used the English version.

We decided to move away from a theory-based classification of findings and instead looked at the data more objectively, by using cluster analysis. Cluster analysis was used mainly as a tool for data reduction (Hair, Black, Babin, Anderson, \& Tatham, 2006). Because of the somewhat large sample ( $\mathrm{n}=$ 
180), we needed to find a method suitable for our purpose of grouping the teachers according to their major concern profiles. The analysis was carried out in the following way. 1 . Sum variables were calculated from the negative items and positive items in each stage separately. Therefore, each teacher had 12 variables representing their interests or concerns in the six C-BAM stages. 2. These variables created a negative and a positive profile for each teacher. 3 . A cluster analysis was performed using kmeans cluster analysis, but a hierarchical clustering with Ward's method would also produce similar results. 4 . The cluster analysis revealed 12 plausible profile types, from which we identified the most important.

One of the most significant methodical challenges was choosing the right clustering method. The main methods for cluster analysis are k-means cluster analysis and hierarchical cluster analysis. Kmeans is, perhaps, simpler since it starts with each case as its own cluster and progresses by combining cases in a way that minimises the variance in each cluster. However, some drawbacks with k-means clustering are that it is dependent on case order, and different results may occur if the analysis is carried out multiple times in a different case order (Xu \& Wunsch, 2009). Therefore, one has to use multiple iterations to see if certain results appear more often than others. We also tried several different kinds of hierarchical clustering methods and a combination of hierarchical and kmeans clustering. The various methods yielded more or less consistent results. Problematically, hierarchical analysis often resulted in one or two large clusters and one or two clusters with only a few teachers. Ultimately, k-means cluster analysis and Hierarchical analysis with Ward's method performed best from a statistical and theoretical viewpoint. The cluster memberships were $78 \%$ similar in these two clustering methods and the clusters were similar in proportion.

\section{Results}

\section{Negative clusters}

Using k-means cluster analysis, as described in the methods section, we grouped teachers into clusters, according to their negative concerns in the 6 concern stages. As described earlier, positive numbers indicate concern while negative numbers indicate a lack of concern (see section 'New questionnaire'). For example, the Concerned cluster in Table 1 has negative concerns in all stages while the Unconcerned cluster does not have negative concerns at any stage. There are three clusters of roughly the same size and one small cluster.

Table 1. Cluster centres (average scores of a cluster) for negative concerns (worries).

\begin{tabular}{lcccc}
\hline & $\begin{array}{c}\text { Unconcerned } \\
(\mathrm{n}=62)\end{array}$ & $\begin{array}{c}\text { Practical } \\
\text { Concerns } \\
(\mathrm{n}=46)\end{array}$ & $\begin{array}{c}\text { Pract. \& } \\
\text { Personal } \\
\text { Concerns } \\
(\mathrm{n}=59)\end{array}$ & $\begin{array}{c}\text { Concerned } \\
(\mathrm{n}=13)\end{array}$ \\
\hline information & $-3,2$ & 2,2 & 2,1 & 5,0 \\
personal & $-5,2$ & $-3,9$ & 1,5 & 3,5 \\
management & $-3,6$ & 2,3 & 2,3 & 4,6 \\
consequence & -6 & $-5,0$ & $-1,7$ & 3,3 \\
collaboration & $-5,6$ & $-3,1$ & $-1,6$ & 2,9 \\
refocusing & $-5,8$ & $-3,5$ & $-1,2$ & 4,6 \\
\hline
\end{tabular}




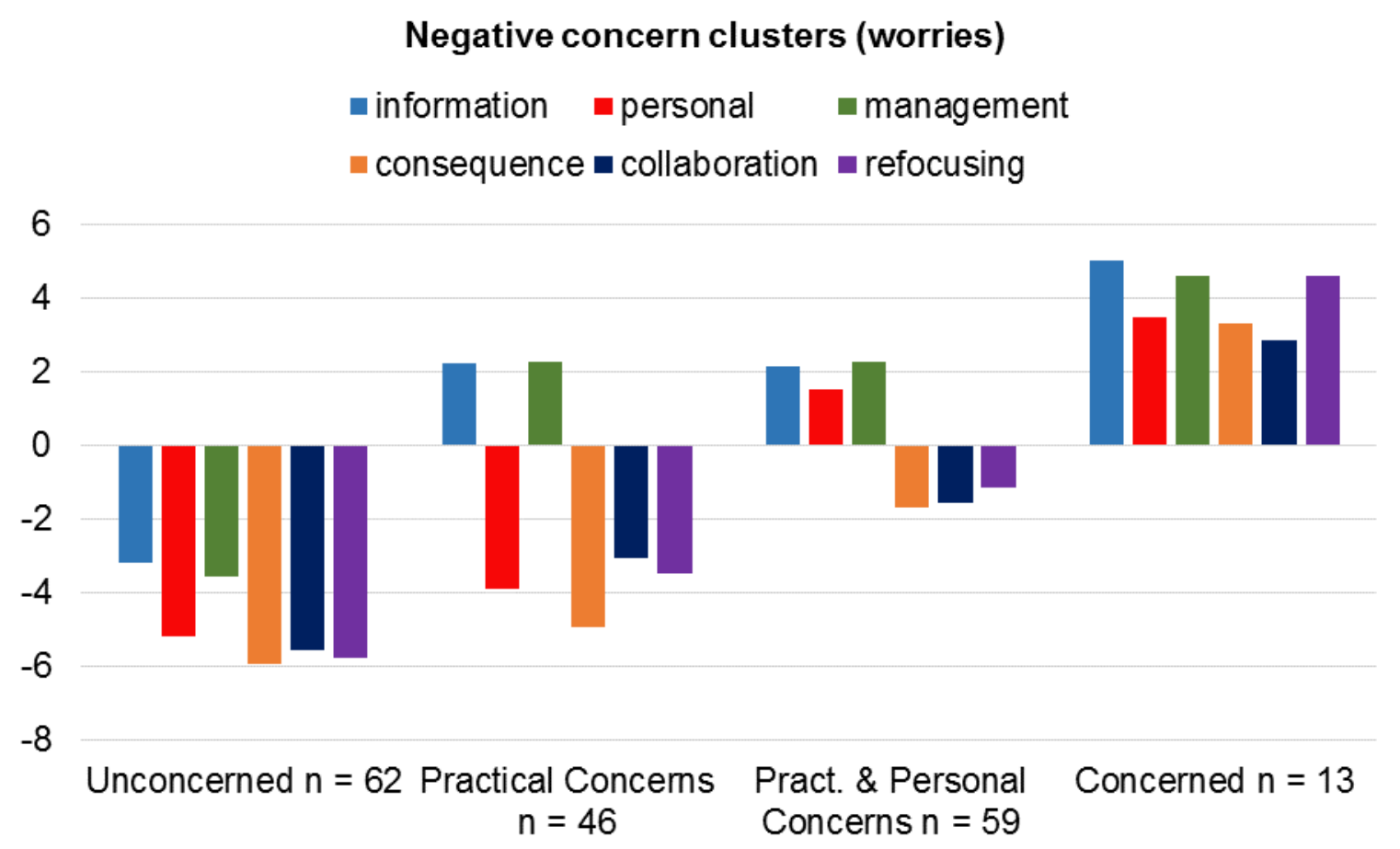

Figure 1. Graphical representation of Table 1.

According to the results above, the largest cluster is the Unconcerned cluster with 62 teachers. These teachers disagreed with most of the negative items, indicating a lack of concern towards RRI teaching. Generally, a lack of negative concerns can be seen as positive, especially if coupled with high positive interests. In some cases, however, lack of concern might be a sign of detachment. The Practical Concerns cluster, with 46 teachers, has concerns mostly in the information and management stages. These teachers need to know more about RRI and the practical implementation of it before possibly carrying on to higher concern stages. The third cluster, with 59 teachers, is similar to the previous cluster with the exception of personal concerns. These teachers might have issues with their professional skills related to RRI teaching. Finally, there were only 13 teachers with extremely negative views on RRI teaching in all concern stages.

\section{Positive clusters}

The positive clusters indicate whether or not teachers are interested or enthusiastic about a certain concern stage. These clusters were analysed in the same manner as the negative clusters. Three distinct clusters were found.

Table 1. Cluster centres (average scores of a cluster) for negative concerns (worries).

\begin{tabular}{lccc}
\hline & $\begin{array}{c}\text { Interested } \\
(\mathrm{n}=30)\end{array}$ & $\begin{array}{c}\text { Fairly } \\
\text { Enthusiastic } \\
(\mathrm{n}=64)\end{array}$ & $\begin{array}{c}\text { Enthusiastic } \\
(\mathrm{n}=86)\end{array}$ \\
\hline information & 2,30 & 4,47 & 5,52 \\
personal &, 80 &,- 06 &, 57 \\
management &, 93 & 2,69 & 4,50 \\
consequence & 1,27 & 2,45 & 4,72 \\
collaboration & 1,23 & 3,48 & 4,79 \\
refocusing & 2,13 & 3,73 & 5,23 \\
\hline
\end{tabular}




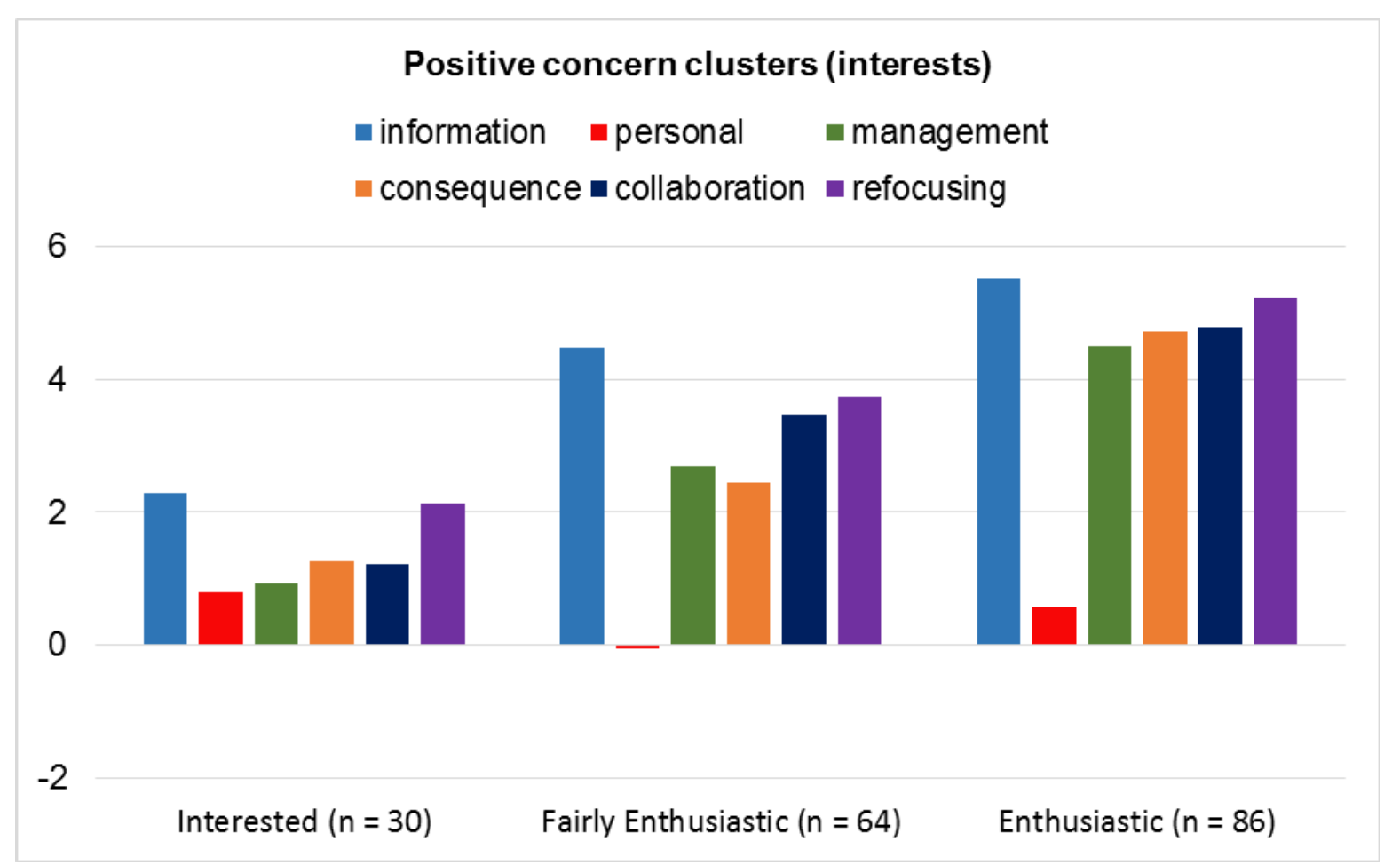

Figure 2. Graphical representation of Table 2.

According to the results above, the first cluster is least interested, while the third cluster is the most interested. All clusters are positively inclined towards RRI teaching. The personal stage does not correlate with the other stages. All clusters have positive concerns in almost all of the stages. The Enthusiastic cluster has the highest values, Fairly Enthusiastic has second highest and the Interested cluster has only moderate interests. The most positive cluster is also the largest, and the least positive cluster is the smallest.

Analysis of the positive concern items did not result in as diverse profiling as the negative concern analysis. On average, all clusters agree with the positive RRI teaching items. The relative concern stage intensities, or the 'shape' of a cluster, are very similar in all groups. By combining the four concerns clusters with the three positive clusters, we could, in theory, identify 12 different concern profile types.

\section{Concern profile types}

The analysis was carried out by combining the negative and the positive concern clusters above. The negative clusters were more informative and diverse and were used as 'primary' clusters. The positive clusters were used as a secondary characteristic of a teacher, and contributed detail to the negative clusters.

Table 3. The Combined concern profile types. Teachers' negative concerns underlie their overall profile, while positive concerns were used as sub-categories.

\begin{tabular}{llc}
\hline Profile type & Sub-category & Num. of teachers / N \\
\hline Carefree- & Enthusiastic & 44 \\
(Unconcerned) & Fairly Enthusiastic & 12
\end{tabular}




\begin{tabular}{llc} 
& Interested & 6 \\
\hline Uncertain - & Enthusiastic & 15 \\
(Pract. \& Personal & Fairly Enthusiastic & 29 \\
Concerns) & Interested & 15 \\
\hline Pragmatic - & Enthusiastic & 22 \\
(Practical & Fairly Enthusiastic & 18 \\
Concerns) & Interested & 6 \\
\hline Worried - & sample too small & 13 \\
(Concerned) & & \\
\hline
\end{tabular}

Table 3 lists the combined profile types and their occurrence. The characteristics of the Carefree type are that they are unconcerned in all of the negative stages and most are enthusiastic in the positive stages. On average, these teachers were clearly more positive than other teachers. They are perhaps easier to convince to teach RRI, but might not address all challenges they are faced with RRI teaching.

The primary characteristics of the next concern profile, the Uncertain, are their practical and personal concerns. These teachers are worried that they might not be able to find enough information on RRI and that there are practical challenges in adopting RRI teaching. What sets them apart from other clusters is that they also have some personal concerns about their ability to teach RRI. They might need some support with professional skills. These teachers were fairly evenly divided on the positive side, with 30 teachers in the 'middle' group (Fairly Enthusiastic) and 15 teachers in other groups. This group of 59 teachers might need somewhat more support than others in their informational, practical and personal concerns, as well as inspiration regarding their positive concerns.

The Pragmatic profile type is quite similar to the Uncertain type. Two main differences are that they do not have too many personal concerns and are more often in the Enthusiastic sub-group. Therefore, they mostly need support with informational and management concerns. Teachers belonging to the Pragmatic or the Carefree profile type are probably the best candidates for becoming early adopters or forerunners.

Finally, we have the Worried cluster, with only 13 teachers. These teachers reported high levels of concern in the negative stages. We assume that they are also less interested in positive aspects of RRI teaching, but we cannot verify this assumption because of the small number of teachers in this cluster. These teachers might be comparable to laggards or late adopters, and might only adopt RRI teaching after others have done so.

\section{Discussion}

The new questionnaire

In the improved Stages of Concern questionnaire (Appendix A) developed in this research, concerns and interests seemed to have a negative correlation. This was most apparent in the Carefree profile type, which had very few concerns and high interest levels, but also in other profile types, for which higher concerns often coincided with having less interest. This negative correlation is perhaps one of the reasons why the original SoC questionnaire did not separate concern and interest into discrete variables. In the old questionnaire, the negative items were reversed, and treated in the same way as the positive items. We argue, however, regardless of the correlation, that concern or worry should be considered as a totally different variable than interest. The positive items had a ceiling effect, which also speaks for separating the variables. 
The ceiling effect was less of an issue with the new questionnaire, since all stages had both negative and positive items. Teachers tend to agree with the positive items, whereas items inquiring about concern better indicated differences in teacher attitudes. The old questionnaire had some stages with only positive items and, therefore, these stages are inflated in most C-BAM studies (Hollingshead, 2009; Overbaugh \& Ruiling, 2008). Our solution for this was to create three negative items and two positive items in each stage. In addition to creating a clearer separation between teachers, this approach improved the comparability of the stages. We identified four main profile types with three subcategories using cluster analysis, which would not have been possible with the old questionnaire. The improved questionnaire seems to work well in identifying teachers based on their interests and concerns regarding RRI in various stages; in future, it can be used also with other teaching innovations and settings worldwide.

\section{Teacher concern profiles and implications of RRI teaching}

In this study, we found four major groups of teachers based on their concerns about RRI teaching. More than half of the teachers belonged to one of the two positive profile types, the Carefree and the Pragmatic. These teachers were more likely than others to have high intensity positive interests, since they were often in the Fairly Enthusiastic or Enthusiastic subgroup. The Uncertain profile type was clearly less positively inclined towards RRI teaching, and had higher than average concerns in the personal stage. The Worried profile type, with strong negative concerns and little positive interest, was the smallest group with 13 teachers.

About one third of the teachers belonged to the Uncertain profile type and had personal concerns regarding RRI teaching. These teachers were concerned about their capability of learning RRI, thought that insufficient opportunities exist for learning RRI and also had information and management concerns. The Uncertain profile type was also less interested in RRI than other teachers on average. The relatively large number of Uncertain teachers calls for better RRI teaching materials as well as motivation regarding the importance of RRI teaching. Such issues are prominent in designoriented PD courses, such as IRRESISTIBLE, where teachers have an important role in developing the teaching modules. Although many teachers are interested and willing to develop teaching materials, there is a need among teachers for somewhat finished (but flexible) materials.

Another issue is the competency of teachers in teaching RRI. Specific teaching skills are sometimes overlooked in teaching reforms. For example, Finnish teachers often lack the practical training to teach ICT, although it is part of the curriculum in Finland. This has created a situation where ICT teaching cannot reach its full potential. To teach RRI, one must know about the interactive processes between science and society as well as what kinds of methods should be used to teach it effectively. RRI demands better conceptualization, pre-service and in-service teacher education and resources, if it is to diffuse across Europe on a wide scale.

The profiles identified in this study may, to some extent, be comparable to early adopters, majority and late adopters (Rogers, 2003). With their strong interests and lack of worry, the Carefree profile type seems the most apparent early adopter candidate. On the other hand, a lack of worry or concern might be a sign of inability to identify practical issues, especially in the beginning of the adoption process. The Pragmatic profile type might also be similar to early adopters. This type has many interests, alongside with some concern in the practical stages, which could help them in identifying and solving practical issues. The question of which profile type is the closest match to early adopters is, however, a research question of its own, and is left for future studies, which will compare teachers' pre and post responses to RRI teaching.

$60 \%$ of our teachers belonged to either the Carefree or the Pragmatic profile type, both of which have high intensities of interest. This percentage is probably higher for teachers participating in a voluntary 
PD course than average school teachers. When disseminating RRI in schools on a wider scale, one must keep in mind that the probability of rejecting RRI could increase, due to smaller numbers of early adopters in proportion to late adopters.

\section{Reflections on RRI teaching}

The diffusion of RRI teaching would benefit from a clear and unified conceptualization for the purpose of science education. First, RRI should be connected with already known concepts such as Nature of Science and Science in Society, and should also indicate the differences between these concepts. The emphasis in Responsible Research and Innovation is on the mutual understanding, shared values and compromises, which would benefit the interplay between societal actors, such as government, industry and NGOs. The goal is not only to understand the interactive processes between these actors but also to define and create novel courses of action between them. The teaching of these kinds of concepts is an enormous challenge for science teachers, and it is safe to say that many teachers in IRRESISTIBLE did not really grasp the full meaning of RRI. Therefore, RRI content and the skills needed to teach it must be better defined in the future.

Another issue that came up in our data (but is not in the focus of this study) was whether or not RRI should be taught explicitly or implicitly. The item inquiring about this issue divided teachers roughly in half. Some teachers think that RRI should be taught directly to students, and that students should be aware of Responsible Research and Innovation as an EU concept. Others thought that RRI should be taught implicitly in the context of other concepts in the science curriculum. RRI could be indirectly included in teaching, for example, by teaching about the societal difficulties of preventing climate change. All profile types were equally divided on this matter, except the few teachers in the Worried profile type, who often though that RRI should be taught explicitly.

Finally, even though the concept of RRI teaching remains largely undefined, teachers favour including RRI in the curriculum in one form or another. This also came across in the additional items. Another finding was that teachers in every profile type agree with the positive items, which indicates interest in RRI teaching. Even the least interested subgroup had some interest in RRI teaching. It is safe to say that if RRI teaching were properly conceptualized and defined, more teachers would belong to one of the two more positive profile types, and would therefore be among the early adopters of RRI teaching.

One reason why it is important to diffuse RRI in schools is that RRI closely relates to solving grand challenges related to agriculture, energy, health, security and preventing natural disasters. These issues are multi-disciplinary and require the attention of multiple societal actors and generations. Therefore, it is important to make future scientists, politicians, entrepreneurs, and other societal actors aware of these issues at an early age.

\section{Acknowledgements}

This study was carried out in the context of the EU project 'IRRESISTIBLE' (FP7-SCIENCE-INSOCIETY--612367) coordinated by Jan Apotheker (University of Groningen, the Netherlands). This research would not have been possible without the support from our irresistible partners in ten European universities who provided valuable feedback for the development of the instruments, and took care of the local data collection. We are grateful to all teachers in all ten countries for participating in the project and expressing their views in the questionnaires. We also thank Prof. Ilka Parchmann (Leibniz Institute for Science and Mathematics Education (IPN), University of Kiel, Germany) for her contribution to choosing and developing C-BAM as a framework. 


\section{References}

de Vocht, M. \& Laherto, A. (in preparation). Profiling teachers based on their professional attitudes about teaching Responsible Research and Innovation. Manuscript in preparation.

de Vocht, M., Laherto, A. \& Parchmann, I. (submitted). Exploring teachers' concerns about bringing Responsible Research and Innovation to European science classrooms. Manuscript submitted for publication.

de Vocht, M., Laherto, A., Parchmann, I. (2015). Teachers' concerns and interests about teaching of “Responsible Research and Innovation" - applying the Concerns-Based Adoption Model. In P. Hästö \& H. Silfverberg (Eds.), Proceedings of the Annual symposium of the Finnish Mathematics and Science Education Research Association 2014 (pp. 103-114). Matematiikan ja luonnontieteiden opetuksen tutkimusseura.

Eagly, A. H. (1992). Uneven progress: Social psychology and the study of attitudes. Journal of Personality and Social Psychology, 63(5), 693-710.

Evers, W. J. G., Brouwers, A., \& Tomic, W. (2002). Burnout and self-efficacy: A study on teachers' beliefs when implementing an innovative educational system in the netherlands. British Journal of Educational Psychology, 72, 227-243.

Hair, J. F. J., Black, W. C., Babin, B. J., Anderson, R. E., \& Tatham, R. L. (2006). Multivariate data analysis (6th ed.). New Jersey, United States: Pearson prentice hall.

Hall, G. E., George, A. A., \& Rutherford, W. L. (1977). Measuring stages of concern about the innovation: a manual for use of the SoC questionnaire. Washington, DC: National Inst. of Education (DHEW).

Hollingshead, B. (2009). The concerns-based adoption model: A framework for examining implementation of a character education program. NASSP Bulletin, 93(3), 166-183.

Kwok, P. (2014). The role of context in teachers' concerns about the implementation of an innovative curriculum. Teaching and Teacher Education, 38, 44-55.

Liu, Y. (2005). Concerns of teachers about technology integration in the USA. European Journal of Teacher Education, $28(1), 35$.

Newhouse, C. P. (2001). Applying the concerns-based adoption model to research on computers in classrooms. Journal of Research on Computing in Education, 33(5)

Overbaugh, R., \& Ruiling, L. (2008). The impact of a federally funded grant on a professional development program: Teachers' stages of concern toward technology integration. Journal of Computing in Teacher Education, 26(2), 45-55.

Rogers, E. M. (2003). Diffusion of innovations (5th ed.). New York, NY: Free Press.

Ruggiu, D. (2015). Anchoring european governance: Two versions of responsible research and innovation and EU fundamental rights as 'Normative anchor points'. Nanoethics, 9, 217-235.

Sutcliffe, H. (2011). A report on responsible research and innovation European Commission.

Tunks, J., \& Weller, K. (2009). Changing practice, changing minds, from arithmetical to algebraic thinking: An application of the concerns-based adoption model (CBAM). Educational Studies in Mathematics, 72, 161-183.

van Aalderen-Smeets, S. I., Walma van der Molen, J. H., \& Asma, L. J. (2011). Primary teachers' attitudes toward science; A new theoretical framework. Science Education, 96(1), 1-22.

Xu, R., \& Wunsch, D. C. (2009). Clustering. Oxford: Wiley-IEEE Press. 


\section{Appendix A}

Table 4. The new C-BAM questionnaire developed for this study.

\begin{tabular}{ll}
\hline & \multicolumn{1}{c}{ Negative concerns (worries) } \\
\hline \multirow{3}{*}{ information } & 3. I am concerned about not getting enough information about RRI. \\
& 4. I am concerned about the availability of useful RRI information. \\
& 5. I do not have enough knowledge of RRI. \\
\hline
\end{tabular}

16. I am not competent in teaching RRI.

personal 27. I am often concerned about my capability of learning things like RRI.

28. I am concerned about not having enough opportunities to develop my RRI teaching.

13. I am concerned about my ability to manage all that RRI teaching requires.

management 15. I do not have enough time and/or resources for RRI teaching.

21. I am concerned about the time spent working with practical problems related to RRI teaching.

24. I am concerned that teaching RRI will have a negative effect on science education.

consequence 29. I do not think that schools will adopt RRI teaching even if it is in the curriculum.

35. I am concerned that RRI teaching does not help students' understanding of science subjects.

1. In general, I am not effective at group work.

collaboration 14. I am concerned that group work when developing RRI teaching will not be efficient.

34. I am concerned that collaboration with other teachers is ineffective in my school.

7. I am concerned that I am not able to develop RRI teaching further in the future.

refocusing 23. I do not want to develop RRI teaching further.

26. I am concerned that the cost of refining RRI teaching outweighs the benefits.

Positive concerns (interests)

information

10. In general, I am interested in learning new content and approaches to teaching.

12. I would like to know what resources are available for RRI teaching.

personal

17. I would like to be more receptive towards new approaches to teaching.

31. I am usually very confident with my teaching skills.

management

8. I can usually overcome problems caused by limited teaching resources and time.

19. I would like to know how to manage everything that RRI teaching involves.

consequence

9. I feel that my school supports me when I decide to bring new teaching approaches to my school.

25. I would like to know how RRI teaching would affect my day-to-day teaching.

2. I often exchange teaching ideas with my colleagues.

collaboration 6. I would like to know if there are opportunities for collaboration in RRI teaching with teachers who work near my school.

refocusing

20. I would like to know what aspects of RRI teaching need further development.

32. I am always trying to improve my teaching. 